B

аску ииты кожи: кАассификация, Аиагностика и дифференциальная диагностика (часть 1)

Хайрутдинов В.Р. *, Белоусова И. Э., Самцов А. В.

ФГБВОУ ВО «Военно-медицинская академия им. С.М.Кирова» Министерства обороны Российской Федерации

194044, Россия, г. Санкт-Петербург, ул. Академика Лебедева, д. 6

Васкулиты кожи - гетерогенная группа заболеваний, характеризующихся воспалением стенки кровеносных сосудов кожи. Многообразие васкулитов кожи, их клиническое сходство, отсутствие четких диагностических критериев и единой терминологии обуславливают крайне сложный процесс диагностики данной группы заболеваний. Дерматовенеролог нередко является первым специалистом, осуществляющим диагностику васкулита. В настоящее время отсутствует единая «Монодисциплинарная» классификация сосудистых повреждений, нет общепринятой терминологии и классификации васкулитов кожи. В отечественной дерматовенерологии васкулиты классифицируют по морфологическим элементам кожной сыпи, а не по этиологии и патогенезу. Это вносит трудности в понимание диагноза разными специалистами, соблюдение преемственности в ведении пациентов.

В статье представлена номенклатура васкулитов международной консенсусной конфреренции Чапел-Хилл 2012 г., дополненная органоспецифическими васкулитами кожи, приведено описание патоморфологических и клинических проявлений данной группы дерматозов, обобщены сведения о современной тактике лечения.

Ключевые слова: васкулиты кожи, классификация васкулитов, номенклатура васкулитов международной консенсусной конференции Чапел-Хилл 2012 г., СНСС2012, лейкоцитокластический васкулит, лечение васкулитов.

Конфрликт интересов: авторы заявляют об отсутствии потенциального конфрликта интересов, требующего раскрытия в данной статье.

Для цитирования: Хайрутдинов В.Р., Белоусова И.Э., Самцов А. В. Васкулиты кожи: классификация, диагностика и дифференциальная диагностика (часть 1). Вестник дерматологии и венерологии. $2020 ; 96$ (1): 18-27. https://doi.org/10.25208/vdv548-2020-96-1-18-27 


\section{C \\ utaneous vasculitis: classification, diagnosis and differential diagnosis (part 1)}

Vladislav R. Khairutdinov*, Irena E. Belousova, Aleksey V. Samtsov

Federal state budgetary educational institution of higher military education "Military Medical Academy named after S.M. Kirov" of the Russian Ministry of Defense

Akademika Lebedeva str., bldg 6, Saint Petersburg, 194044, Russian Federation

Cutaneous vasculitis is a heterogeneous group of diseases caused by inflammation of the blood vessel wall of the skin. The variety of cutaneous vasculitis, their clinical similarity, lack of clear diagnostic criteria and common terminology cause an extremely complex process of diagnosis of this group of diseases. A dermatologist is often the first specialist to diagnose vasculitis. Currently there is no single "monodisciplinary" classification of $v$ ascular damage, there is no generally accepted terminology and classification of cutaneous vasculitis. In domestic dermatovenerology, vasculitis is classified according to the morphological elements of the skin rash, and not by etiology and pathogenesis. This makes it difficult for different specialists to understand the diagnosis and maintain continuity in the management of patients.

The article presents the nomenclature of vasculitis of the 2012 revised international Chapel Hill consensus conference nomenclature of vasculitides, supplemented by organ-specific cutaneous vasculitis, describes the pathomorphological and clinical manifestations of this group of dermatoses, summarizes information about modern treatment tactics.

Keywords: cutaneous vasculitis, classification of vasculitis, Chapel Hill consensus conference nomenclature of vasculitides, CHCC2012, leukocytoclastic vasculitis, treatment of vasculitis.

Conflict of interest: the authors state that there is no potential conflict of interest requiring disclosure in this article.

For citation: Vladislav R. Khairutdinov, Irena E. Belousova, Aleksey V. Samtsov. Cutaneous vasculitis: classification, diagnosis and differential diagnosis (part 1). Vestnik Dermatologii i Venerologii. 2020; 96 (1): 18-27. https://doi. org/10.25208/vdv548-2020-96-1-18-27 
В настоящее время нет общепринятой терминологии и классификации васкулитов и сосудистых нарушений кожи. Этот вопрос является одним из наиболее сложных, запутанных и дискутабельных не только в дерматовенерологии, но и в других дисциплинах. Дополнительные трудности в работе различных специалистов, соблюдении преемственности в ведении пациентов с васкулитами обусловлены существованием нескольких «монодисциплинарных» классификаций и определений сосудистых повреждений. Наиболее полная инфрормация о васкулитах представлена в номенклатуре васкулитов международной консенсусной конференции Чапел-Хилл 2012 г. (Chapel Hill CHCC2012). Номенклатура Чапел-Хилл не является классификацией, в ней нет диагностических критериев. Она включает информацию о всех формах васкулитов, достаточно объемна и неудобна для клинической работы. Основная цель создания номенклатуры CHCC2012 - это построение единого междисциплинарного подхода в понимании проблемы сосудистых повреждений, формулировка определений, согласованных всеми специалистами. Классификация васкулитов в номенклатуре Чапел-Хилл 2012 г. осуществляется в зависимости от диаметра поражаемых сосудов, этиологии и патогенетических особенностей воспалительного процесса $[1,2]$.

В отечественной дерматовенерологии все еще используется классификация васкулитов, разработанная на основе номенклатуры Чапел-Хилл 1994 г. B ее основу положен принцип классификации заболеваний не по этиологии и патогенезу, а по морфологическим элементам кожной сыпи. Недостатком подобного подхода является объединение совершенно разных васкулитов, сходных по клиническим проявлениям, в один дерматоз, и наоборот, разделение одного заболевания, характеризующегося различными элементами сыпи, на несколько васкулитов. Например, хорошо известный дерматовенерологам термин «папуло-некротический васкулит», согласно последним иммунологическим и патоморфологическим исследованиям, объединяет ANCA-ассоциированные васкулиты, IgA- и IgM/IgG васкулиты, лекарственно-индуцированные васкулиты и васкулиты, ассоциированные со злокачественными новообразованиями, васкулиты, ассоциированные с вирусным гепатитом В [1-3].

Кожа является одним из наиболее часто поражаемых органов при васкулитах. Номенклатура Чапел-Хилл 2012 г. не подходит для использования В практической деятельности. Для стандартизации определений, диагностических критериев и валидации классификации недавно была создана специальная рабочая группа экспертов, в которую вошли специалисты Европейской академии дерматологии, Американского общества дерматологов и ревматологов и др. (формирование дерматологической номенклатуры D-CHCC) [2, 3].

\section{Определение}

Васкулиты кожи - гетерогенная группа заболеваний, причиной которых является воспаление стенки кровеносных сосудов кожи. Системный васкулит - это васкулит с поражением как минимум одного органа, кроме кожи [2].

\section{Эпидемиология}

Васкулиты относятся к редким заболеваниям. Значение показателя распространенности всех васкулитов варьирует, по оценке разных исследователей, от 0,4 до 14 и более случаев на 100 тыс. населения. Заболеваемость васкулитами сосудов малого диаметра в среднем составляет 3 случая на 100 тыс. населения в год. У детей наиболее часто встречается IgA-васкулит 3-27 случаев на 100 тыс. населения в год [4-8].

\section{Классификация}

Васкулиты кожи включают несколько клинических вариантов поражения сосудов (табл. 1) [1]:

1. Поражение кожи как одно из проявлений (симптом) системного васкулита.

2. Системные васкулиты с преимущественным поражением кожи.

3. Органоспецифические васкулиты (васкулиты одного органа).

Согласно номенклатуре Чапел-Хилл 2012 г., сосуды делятся на малые и средние в зависимости от их структуры и функции, а не диаметра. К сосудам малого диаметра относятся интрапаренхимальные малые артерии, артериолы, капилляры, посткапиллярные венулы и малые вены. Сосуды среднего диаметра включают магистральные артерии и вены, а также их начальные ветви. К сосудам крупного диаметра относятся аорта и ее основные ветви. В дерме и подкожной клетчатке есть только сосуды малого диаметра, однако при васкулитах сосудов крупного или среднего диаметра более мелкие сосуды также могут в той или иной степени вовлекаться в воспалительный процесс.

При васкулитах кожи обычно наблюдается поражение сосудов малого диаметра, которые делят на две большие группы: ANCA-ассоциированные (ANCA antineutrophil cytoplasmic antibodies - антинейтрофильные цитоплазматические антитела) и васкулиты, обусловленные отложением иммунных комплексов [9-10].

ANCA-ассоциированные васкулиты диффреренцируют на основании клинических проявлений и патоморфологических изменений. Выделяют следующие клинические фрормы: микроскопический полиангиит, гранулематоз с полиангиитом (устар. гранулематоз Вегенера) и эозинофильный гранулематоз с полиангиитом (устар. болезнь Чарга - Стросса). Дополнительно, на основании серологических исследований, ANCA-acсоциированные васкулиты делят на ANCA-позитивные - с антителами к миелопероксидазе (MPO-ANCA) и к протеиназе-3 (PR3-ANCA), а также ANCA-негативные. Следует отметить, что эти клинико-морфологические фрормы и серотипы ANCA имеют значение для прогнозирования исходов заболевания [9-10].

В ряде наблюдений авторы описывают ограниченное поражение кожи при системных ANCA-ассоциированных васкулитах. В подавляющем большинстве случаев это васкулиты, индуцированные лекарственными препаратами (лекарственно-индуцированный ANCA-acсоциированный васкулит), при которых чаще выявляются антитела MPO-ANCA, чем PR3-ANCA. Критерием диагностики является наличие связи между приемом медикаментов и началом развития изменений в коже, а также быстрое разрешение высыпаний после прекращения поступления лекарственного препарата в организм [11-13]. 
Таблица 1. Варианты вовлечения сосудов кожи, согласно номенклатуре васкулитов международной консенсусной конференции (Чапел-Хилл 2012 - СНСС2012) [1, 2]

Table 1. Variants of cutaneous vascular involvement according to the international consensus conference nomenclature of vasculitides (Chapel Hill 2012 — CHCC2012) [1, 2]

\begin{tabular}{|c|c|c|}
\hline \multirow[b]{2}{*}{ Категория } & \multicolumn{2}{|c|}{ Варианты поражения кожи } \\
\hline & проявление системного васкулита & $\begin{array}{c}\text { системный васкулит с преимущественным } \\
\text { поражением кожи или органоспецифический } \\
\text { васкулит кожи }\end{array}$ \\
\hline \multicolumn{3}{|l|}{ І. Васкулиты сосудов крупного диаметра: } \\
\hline $\begin{array}{c}\text { - Неспецифический аортоартериит } \\
\text { (артериит Такаясу) }\end{array}$ & Нет & Нет \\
\hline — Гигантоклеточный артериит & Редко & Нет \\
\hline \multicolumn{3}{|l|}{ II. Васкулиты сосудов среднего диаметра: } \\
\hline -Узелковый периартериит & Да & Да \\
\hline - Болезнь Кавасаки & Нет & Нет \\
\hline \multicolumn{3}{|l|}{$\begin{array}{l}\text { III. Васкулиты сосудов малого диаметра: } \\
\text { 1. ANCA-ассоциированные васкулиты: }\end{array}$} \\
\hline — Микроскопический полиангиит & Да & Да \\
\hline $\begin{array}{c}\text { - Гранулематоз с полиангиитом } \\
\text { (болезнь Вегенера) }\end{array}$ & Да & Да \\
\hline $\begin{array}{c}\text { - Эозиносиильный гранулематоз } \\
\text { с полиангиитом (болезнь Чарга - Стросса) } \\
\text { 2. Иммунокомплексные васкулиты: }\end{array}$ & Да & Да \\
\hline $\begin{array}{c}\text {-Болезнь с образованием антител } \\
\text { к базальной мембране клубочков (анти-GBM } \\
\text { болезнь, устар. синдром Гудпасчера) }\end{array}$ & Нет & Нет \\
\hline -Криоглобулинемический васкулит & Да & Да \\
\hline — IgA-васкулит (болезнь Шенлейна — Геноха) & Да & Да \\
\hline $\begin{array}{c}\text { - Гипокомплементемический уртикарный } \\
\text { васкулит (анти-С1q васкулит) }\end{array}$ & Да & Да \\
\hline
\end{tabular}

\begin{tabular}{|c|c|c|}
\hline $\begin{array}{l}\text { І. Васкулит с вариабельным поражением } \\
\text { сосудов: }\end{array}$ & & \\
\hline - Болезнь Бехчета & Да & Да \\
\hline - Синдром Когана & Редко & Нет \\
\hline \multicolumn{3}{|l|}{$\begin{array}{l}\text { II. Васкулиты, ассоциированные с системными } \\
\text { заболеваниями: }\end{array}$} \\
\hline $\begin{array}{c}\text { - Волчаночный васкулит } \\
\text { — Ревматоидный васкулит } \\
\text { - Васкулит при саркоидозе } \\
\text { — Васкулит при других системных } \\
\text { заболеваниях }\end{array}$ & $\begin{array}{l}\text { Да } \\
\text { Да } \\
\text { Да } \\
\text { Да }\end{array}$ & $\begin{array}{l}\text { Да } \\
\text { Да } \\
\text { Да } \\
\text { Да }\end{array}$ \\
\hline \multicolumn{3}{|l|}{$\begin{array}{c}\text { III. Васкулиты с установленной (вероятной) } \\
\text { этиологией: }\end{array}$} \\
\hline $\begin{array}{c}\text { - Криоглобулинемический васкулит, } \\
\text { ассоциированный с вирусным гепатитом С }\end{array}$ & Да & Да \\
\hline $\begin{array}{c}\text { — Васкулит, ассоциированный с вирусным } \\
\text { гепатитом В }\end{array}$ & Да & Да \\
\hline $\begin{array}{c}\text { - Лекарственно-индуцированный } \\
\text { иммунокомплексный васкулит }\end{array}$ & Да & Да \\
\hline $\begin{array}{c}\text { - Лекарственно-индуцированный ANCA- } \\
\text { ассоциированный васкулит }\end{array}$ & Да & Да \\
\hline - Септический васкулит & Да & Да \\
\hline $\begin{array}{c}\text { - Васкулит, ассоциированный } \\
\text { со злокачественными новообразованиями }\end{array}$ & Да & Да \\
\hline \multicolumn{3}{|l|}{$\begin{array}{l}\text { IV. Органоспецифические васкулиты - } \\
\text { васкулиты одного органа (номенклатура } \\
\text { CHCC2012 дополнена): }\end{array}$} \\
\hline - $\lg \mathrm{M} / \lg$ в васкулит & Нет & Да \\
\hline $\begin{array}{c}\text { - Нодулярный (узловатый) васкулит } \\
\text { (индуративная эритема Базена) }\end{array}$ & Нет & Да \\
\hline — Эритема возвышающаяся стойкая & Нет & Да \\
\hline $\begin{array}{c}\text { - Гипергаммаглобулинемический пятнистый } \\
\text { васкулит (гиперглобулинемическая пурпура } \\
\text { Вальденстрема) }\end{array}$ & Нет & Да \\
\hline $\begin{array}{c}\text { - Нормокомплементемический уртикарный } \\
\text { васкулит }\end{array}$ & Нет & Да \\
\hline
\end{tabular}


Все васкулиты, обусловленные отложением иммунных комплексов, за исключением анти-GBM болезни (Glomerular Basement Membrane lgG antibody - болезнь с образованием антител к базальной мембране клубочков), могут поражать сосуды кожи. При IgA-васкулите (болезнь Шенлейна - Геноха, геморрагический васкулит) и IgM/lgG-васкулите отмечается воспаление посткапиллярных венул преимущественно нижних конечностей. Для других васкулитов, обусловленных отложением иммунных комплексов, характерно поражение не только посткапиллярных венул, но и других кровеносных сосудов, а также высыпания распространенного характера. Воспалительный процесс в сосудистой стенке развивается после фиксации на ней циркулирующих иммунных комплексов, образованных различными антигенами (инфекционные агенты, лекарственные препараты и др.) и антителами к ним. Воспаление приводит к повреждению эндотелия и окружающих тканей [14-16].

В номенклатуре Чапел-Хилл 2012 г. болезнь Бехчета и синдром Когана отнесены к васкулитам с вариабельным поражением сосудов.

Органоспецифические васкулиты (васкулиты одного органа) характеризуются клиническими, гистологическими и патофизиологическими отличиями от системных васкулитов. Номенклатура Чапел-Хилл, содержащая в разделе органоспецифических васкулитов лишь термин «кожный лейкоцитокластический васкулит», была дополнена экспертной группой дерматологов несколькими нозологическими формами [16].

Кроме васкулитов, выделяют другие сосудистые поражения кожи, такие как окклюзионные васкулопатии и пигментно-пурпурозные дерматозы (гемосидерозы).

\section{Диагностика и дифференциальная диагностика}

Пациенты с васкулитами кожи обычно предьявляют жалобы на наличие сыпи, чувство жжения и боли в области высыпаний, иногда беспокоит зуд.

Высыпания на коже могут быть представлены следующими первичными морфологическими элементами: геморрагическими пятнами (пурпура), нередко выступающими над уровнем кожи (геморрагические папулы, пальпируемая пурпура), узлами, пузырями с геморрагическим содержимым, волдырями (существующими >24 часов). Наиболее часто встречаются мелкие (1-3 мм) геморрагические пятна - петехии. Геморрагические пятна могут иметь более крупные размеры (>3 мм) - экхимозы или сливаться, образуя сетчатый рисунок - ретикулярную пурпуру. Некоторые авторы с целью диффреренциальной диагностики васкулитов и окклюзионных васкулопатий выделяют «воспалительный» и «невоспалительный» вариант пурпуры. В первом случае по периферии геморрагических пятен определяется выраженная эритема, свидетельствующая об активном (первичном) воспалительном процессе в дерме. Во втором - эритема отсутствует или минимальна, пурпура развивается вследствие окклюзии сосудов, которая практически не вызывает воспаления по перисрерии [16].

Вторичные элементы кожной сыпи включают точечные (очаговые) или обширные некрозы (инфраркты) кожи (в первом случае наблюдаются папуло-некротические высыпания, во втором - формирование струпа), язвы, поствоспалительные гиперпигментные пятна, рубцы (часто небольших размеров и округлой формы - «штампованные») [15, 17].
Высыпания могут локализоваться на любом участке кожи и видимых слизистых оболочках, но наиболее часто встречаются на нижних конечностях, особенно голенях и стопах, возможно усиление высыпаний в зонах компрессии. Количество элементов сыпи может варьировать от нескольких единиц до нескольких сотен или тысяч. Пурпура обычно появляется в течение нескольких дней и самостоятельно разрешается через 2-3 недели [15, 17].

Стандартного протокола обследования пациентов с васкулитами кожи не существует. Скрининговые тесты должны быть направлены на выяснение возможной причины развития заболевания и степени вовлечения других органов в воспалительный процесс. Выполняется клинический и биохимический (основные показатели метаболизма, функции печени и почек) анализы крови, общий анализ мочи, серологическое исследование крови на маркеры вирусных гепатитов В и С, ВИЧ-инфекцию, ревматоидный фрактор, антинуклеарные антитела. Специфические лабораторные тесты для большинства васкулитов отсутствуют, часто отмечаются неспецифические проявления системной воспалительной реакции - лейкоцитоз, повышенный уровень С-реактивного белка или артралгия, которые не являются достаточным доказательством васкулита и его системности. В ряде случаев в сыворотке больных определяют уровень криоглобулинов, антинейтрофильных цитоплазматических антител и антител к фактору комплемента C1q $[18,19]$.

Для верификации диагноза васкулита требуется проведение диагностической биопсии кожи с последующим гистологическим и, в ряде случаев, прямым иммунофрлуоресцентным исследованием. Патоморфологические изменения при васкулитах кожи зависят от времени с момента развития процесса и проводимого лечения. Например, для диагностики лейкоцитокластического васкулита желательно выполнить биопсию в интервале 24-48 ч после появления высыпаний на коже. Прямое иммунофрлюоресцентное исследование кожи необходимо проводить в еще более короткие сроки (8-24 ч) в связи с тем, что иммуноглобулины быстро разрушаются [15].

Термин «лейкоцитокластический васкулит» не отражает нозологическую принадлежность сосудистых поражений, является патоморфологическим определением типа (паттерна) повреждения стенки сосудов. Этот морфологический вариант воспаления может наблюдаться при различных васкулитах, отличающихся по механизму развития, а также при вторичных сосудистых поражениях (тканевая реакция по периферии язв, инфицированные повреждения). Для лейкоцитокластического васкулита характерны следующие изменения: наличие нейтрофильных гранулоцитов в стенке и вокруг поверхностных и глубоких сосудов дермы (периваскулярные нейтрофильные инфильтраты, в более старых очагах - смешанные инфильтраты), фррагменты ядер нейтрофилов (ядерная пыль, лейкоцитоклазия), отек, фрибриноидный некроз и разрушение стенок сосудов, выход эритроцитов в окружающие ткани (рис. 1, 2) $[14,20]$.

Узелковый периартериит - некротизирующий системный артериит сосудов среднего или малого диаметра без развития гломерулонефрита, васкулита артериол, капилляров или венул, при котором не обнаруживаются антитела к цитоплазме нейтрофилов. При кожной форме узелкового периартериита 


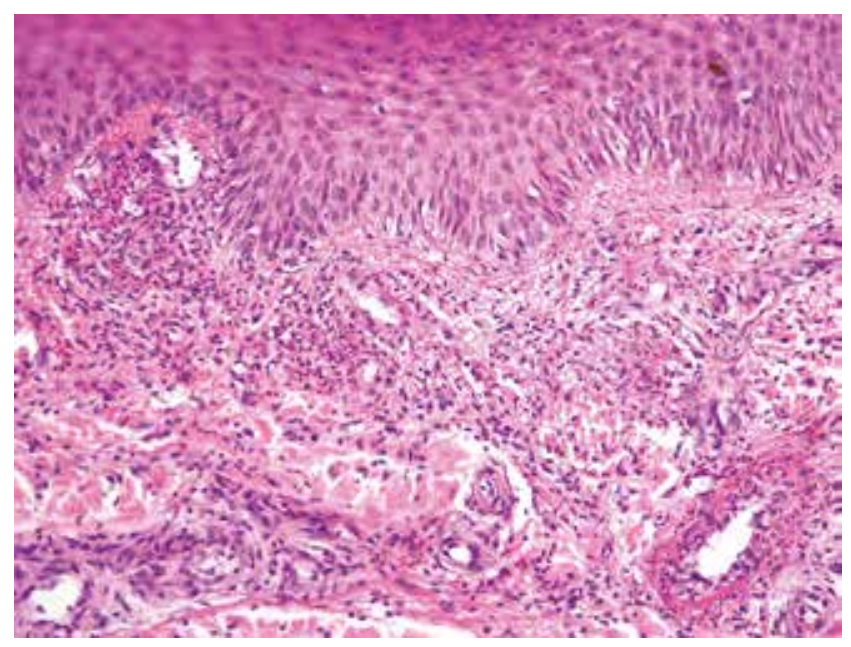

Рис. 1. Лейкоцитокластический васкулит. Нейтрофильные гранулоциты в стенке и вокруг поверхностных сосудов дермы, фрагменты ядер нейтросиилов (ядерная пыль, лейкоцитоклазия), отек, фибриноидный некроз стенок сосудов Fig. 1. Leukocytoclastic vasculitis. Neutrophilic granulocytes in the wall and around the dermis' surface vessels, fragments of neutrophil nuclei (nuclear dust, leukocytoclasia), edema, and fibrinoid necrosis of vessel walls

поражаются малые артерии и артериолы в подкожной клетчатке, вены не затрагиваются. В дифореренциальной диагностике узелкового периартериита с микроскопическим полиангиитом учитывается, что при первом заболевании всегда поражаются только артерии, но не посткапиллярные венулы. В отличие от нодулярного васкулита (индуративная эритема Базена) при узелковом периартериите воспаление не распространяется на адвентицию артерий и на дольки подкожной клетчатки [2, 9, 20].

ANCA-ассоциированные васкулиты в начале заболевания могут быть ограничены поражением только сосудов кожи. Наличие антител к цитоплазме нейтрофилов является обязательным условием для диагностики ANCA-ассоциированного васкулита, ограниченного кожей, поскольку клинические проявления заболевания характеризуются разнообразием, а диаметр поражаемых сосудов не является строго специфичным признаком [21].

Различают несколько патоморфологических вариантов поражения кожи при системных ANCA-ассоциированных васкулитах [9, 10]:

1. Лейкоцитокластический васкулит посткапиллярных венул дермы. Клинические проявления: геморрагические пятна, папулы, реже узлы.

2. Васкулит малых артерий или артериол. Клинически представлен «воспалительной» ретикулярной пурпурой или ливедо, узлами. В некоторых случаях могут наблюдаться очаговые некрозы (инфаркты) кожи.

3. Внесосудистое гранулематозное воспаление без васкулита (гранулематоз с полиангиитом и эозинофильный гранулематоз с полиангиитом).

4. Другие слизисто-кожные поражения без васкулита (гиперпластический гингивит при гранулематозе с полиангиитом).

Микроскопический полиангиит является ANCA-acсоциированным васкулитом, при котором поражаются все кровеносные сосуды кожи малого диаметра (артериолы, капилляры, венулы), часто с лейкоцитоклазией,

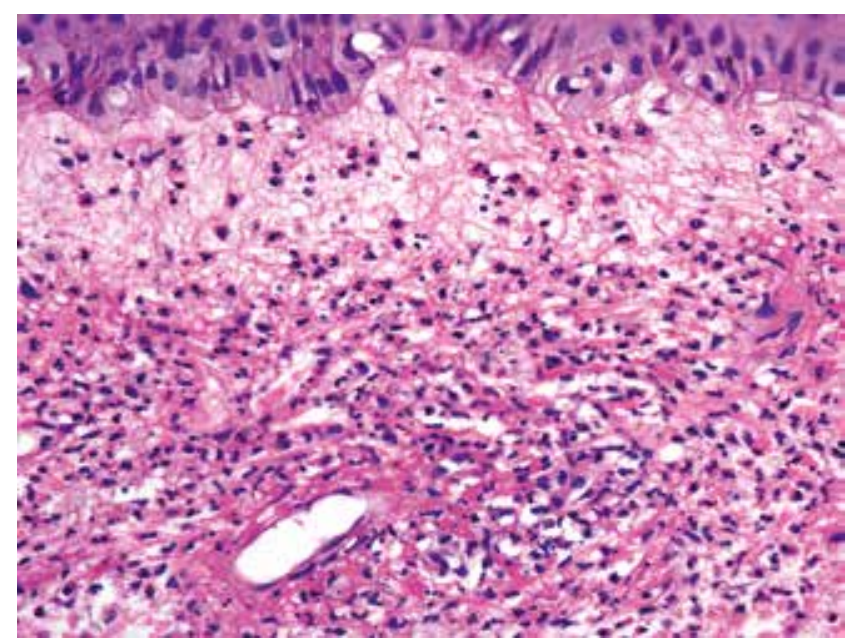

Рис. 2. Лейкоцитокластический васкулит. Выраженный отек сосочковой части дермы. Периваскулярный нейтрофильный инфильтрат с явлениями лейкоцитоклазии

Fig. 2. Leukocytoclastic vasculitis. Severe edema of the papillary dermis. Perivascular neutrophilic infiltrate with leukocytoclasia

и не встречаются отложения иммунных комплексов. Часто в процесс воспаления вовлекаются подкожные сосуды, включая артерии. При микроскопическом полиангиите отсутствует гранулематозное воспаление в коже или других органах [2, 9, 20].

При гранулематозе с полиангиитом происходит поражение тех же сосудов, что и при микроскопическом полиангиите, но в сопровождении гранулематозного инфильтрата. Формирование гранулем может не затрагивать кровеносные сосуды, характерно палисадообразное расположение эпителиоидных и гигантских клеток вокруг очагов базофильных некрозов, количество эозинофилов незначительно. Может встречаться интерстициальный вариант гранулематозного воспаления [2, 9, 10].

Гистологическая картина изменений в коже при эозинофильном гранулематозе с полиангиитом включает периваскулярные эозинофрильные инфильтраты в сочетании с проявлениями васкулита - от нейтрофилльного лейкоцитокластического варианта (без выраженной лейкоцитоклазии) с обилием эозинофилов до васкулита артериол, малых артерий или вен. Внесосудистые изменения представлены диффузными интерстициальными инфильтратами в дерме, содержащими многочисленные эозинофилы и «фигуры пламени» - деградированные коллагеновые волокна с отложениями белков гранул эозинофилов, окруженные гистиоцитами и эозинофилами, а также дермальными гранулемами из палисадообразно расположенных макрофагов с примесью эозинофилов вокруг эозинофильных зон некробиоза (гранулема Чарга - Стросса). В анамнезе пациентов имеется бронхиальная астма [9, 10, 20].

ANCA-негативный вариант ANCA-ассоциированного васкулита встречается достаточно редко, обычно на начальных стадиях заболевания. Диагностика в таких ситуациях крайне затруднительна и осуществляется ретроспективно, после появления у пациента соответствующих антител [2].

Криоглобулинемический васкулит характеризуется развитием лейкоцитокластического васкулита 
посткапиллярных венул (реже малых вен и артериол) с отложением депозитов из криоглобулинов в пораженных сосудах. В сыворотке крови больных обнаруживают криоглобулины II и III типа. Описаны случаи моноклональной криоглобулинемии I типа, однако при высоких титрах криоглобулинов I типа чаще наблюдается не васкулит, а окклюзионная васкулопатия, вызванная агрегацией криоглобулинов в просвете мелких сосудов. При окклюзионной васкулопатии у пациента нет клинических проявлений васкулита - пальпируемой пурпуры, наблюдается развитие геморрагических некрозов, характерна «невоспалительная» сетчатая пурпура [22-23].

Патоморфологические изменения при $\lg A$-васкулите (устар. пурпура Шенлейна - Геноха) и IgM/lgG-васкулите практически неотличимы и имеют гистологическую картину лейкоцитокластического васкулита посткапиллярных венул (реже артериол и малых вен кожи) (см. рис. 1, 2). Дифференцировать заболевания можно методом прямой иммунофрлуоресценции при верификации класса иммуноглобулинов, образующих депозиты в стенке кровеносных сосудов (IgA1 или $\lg$ М и $\operatorname{lgG}$ соответственно). Диагноз $\lg$ А-васкулита или $\mathrm{lgM} / \mathrm{lgG}$-васкулита устанавливают в тех случаях, когда исключены другие васкулиты иммунных комплексов - криоглобулинемический, васкулиты при моноклональной гаммапатии, ревматоидном артрите, дерматомиозите, системной красной волчанке. Например, при выявлении криоглобулинов класса IgA устанавливается диагноз криоглобулинемический васкулит, а не болезнь Шенлейна - Геноха, так как IgA-васкулит по рекомендации ACR (American College of Rheumatology) диагностируется при наличии двух критериев из четырех: 1) пальпируемая пурпура; 2) возраст $\leq 20$ лет; 3) острая боль в животе; 4) при гистологическом исследовании выявляют гранулоциты в стенке артериол или венул. По критериям EULAR/ PRINTO/PRES (European League Against Rheumatism/ Paediatric Rheumatology International Trials Organisation/ Paediatric Rheumatology European Society) для подтверждения диагноза IgA-васкулита обязательно должны быть высыпания в виде пальпируемой пурпуры или петехий, с преобладающей локализацией на коже нижних конечностей, при отсутствии тромбоцитопении и коагулопатии, и одно из следующих условий: 1) боль в животе; 2) положительная реакция прямой иммунофлюоресценции c $\lg$; 3) артрит или артралгия; 4) поражение почек (гематурия или протеинурия) [2, 8, 23, 24].

При гипокомплементемическом уртикарном васкулите (анти-С1q васкулит) более чем у половины пациентов выявляются антитела к С1q фактору комплемента (анти-C1q). Патоморфологические изменения в коже представлены фибриноидным некрозом стенки сосудов с периваскулярной лейкоцитоклазией, ограниченным отеком сосочкового слоя дермы. При прямой иммунофлуоресценции в сосудистой стенке выявляются депозиты компонентов комплемента и иммуноглобулинов. Анти-С1q васкулит следует дифференцировать с нейтрофильным уртикарным дерматозом, который так же как и гипокомплементемический уртикарный васкулит, встречается у больных СКВ и при некоторых аутовоспалительных синдромах. При нейтрофильном уртикарном дерматозе на коже больных имеются бледные гиперемические пятна, папулы и бляшки, но не волдыри. При гистологическом исследовании кожи лейкоцитокластический васкулит не встречается, наблюдаются периваскулярные и дифффузные интерстициальные нейтрофильные инфрильтраты, нейтрофрильный эпидермотропизм - миграция нейтрофилов в эпидермис, волосяные фолликулы, сальные и потовые железы. Нормокомплементемический уртикарный васкулит относится к нейтрофильным дерматозам. Клинические проявления поражения кожи при этой форме васкулита не отличаются от анти-С1q васкулита. В сыворотке крови отмечается нормальный уровень фракций комплемента и не выявляются анти-С1q антитела. При обоих вариантах уртикарного васкулита выявляется изолированное поражение посткапиллярных венул, в то время как при васкулитах, ассоциированных с системными заболеваниями (СКВ, ревматоидный артрит и др.), наблюдается воспаление более глубоких и крупных сосудов [26-28].

При болезни Бехчета на ранней стадии любых высыпаний на коже, за исключением акнеформных (фолликулярных) пустул, выявляются поражения сосудов малого диаметра с отеком эндотелия и лейкоцитоклазией, иногда васкулит с фрибриноидным некрозом. Тромбоз крупных сосудов развивается при васкулите vasa vasorum. Гистологическое исследование узлов позволяет обнаружить в гиподерме лейкоцитокластический септальный васкулит с обилием гистиоцитов. В отличие от узловатой эритемы при болезни Бехчета не наблюдается формирование радиальных гранулем Мишера и инфильтратов в жировых дольках подкожной клетчатки. При исследовании биоптатов кожи в более поздние сроки можно выявить только периваскулярные лимфоцитарные инфильтраты и лимфоциты в стенке сосудов. Этот факт вызвал дискуссию о том, относится ли болезнь Бехчета к васкулопатиям или лимфоцитарным васкулитам [29].

Нодулярный (узловатый) васкулит (индуративная эритема Базена) представляет лобулярный панникулит с васкулитом сосудов гиподермы. Наиболее часто выявляется поражение венул жировых долек, реже - малых лобулярных и септальных вен, еще реже - изолированное поражение малых вен и артерий септальных перегородок подкожной клетчатки (рис. 3, 4). Кроме васкулита, патоморфологические изменения кожи могут включать коагуляционный и казеозный некроз, а также нейтрофильные, гранулематозные или лимфоцитарные инфильтраты. При дифференциальной диагностике с острой узловатой эритемой учитывают, что для нодулярного васкулита характерно хроническое течение, поражение сгибательных поверхностей голеней, изъязвление узлов, при гистологическом исследовании выявляется поражение долек гиподермы. Узловатая эритема имеет острое течение, узлы локализуются на переднебоковых поверхностях голеней, не изъязвляются, патоморфологические изменения представлены септальным панникулитом без васкулита [30].

Эритема возвышающаяся стойкая - это нейтрофилльный дерматоз (классифицируется как поражение дермы с васкулитом), при котором отмечается хронический локализованный фриброзирующий лейкоцитокластический васкулит. Изменения в коже начинаются с поражения посткапиллярных венул (отложения фиирина в стенках сосудов, лейкоцитоклазия), в стенках часто обнаруживаются депозиты из иммунных комплексов. Периваскулярные инфильтраты смешанные, включают нейтрофиильные гранулоциты (присутствуют всегда), гистиоциты, плазматические клетки и эозинофильные лейкоциты (рис. 5). На ранних стадиях развивается 


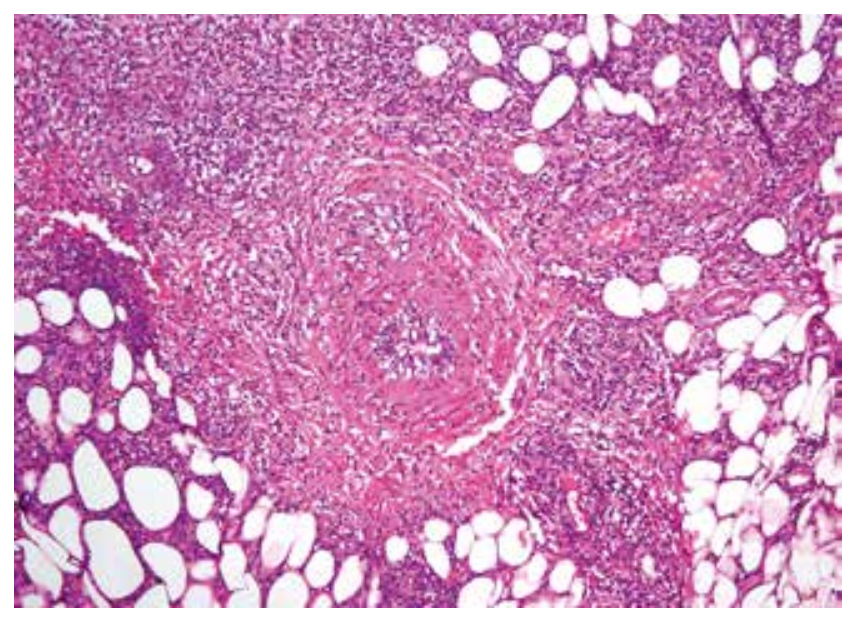

Рис. 3. Нодулярный (узловатый) васкулит. Поражение септальной артерии подкожной клетчатки (септальный васкулит). Инфильтрация нейтрофильными лейкоцитами мышечного слоя, отек и пролиферация эндотелиальных клеток Fig. 3. Nodular (erythema induratum) vasculitis. Lesions of the septal artery of the hypoderm (septal vasculitis). Muscular layer neutrophilic leukocyte infiltration, edema and proliferation of endothelial cells

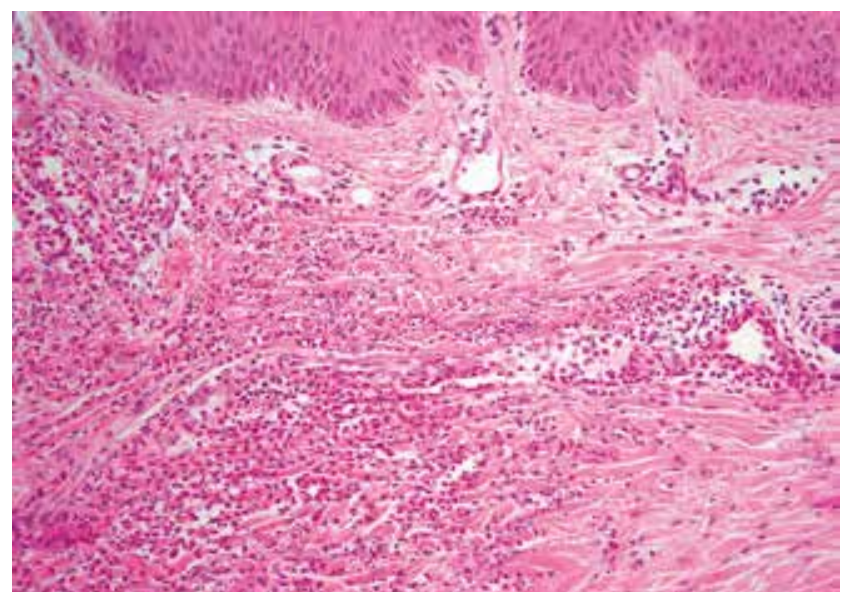

Рис. 5. Эритема возвышающаяся стойкая. Инфильтрация дермы нейтрофильными лейкоцитами. Лейкоцитокластический васкулит сосудов малого калибра

Fig. 5. Erythema elevatum diutinum. Infiltration of the dermis with neutrophilic leucocytes. Leukocytoclastic vasculitis of small-caliber vessels

выраженный отек сосочковой дермы, который клинически иногда ошибочно расценивается как везикуляция. Позже в периваскулярных инфильтратах увеличивается количество гистиоцитов, отмечается пролиферация веретенообразных клеток, развивается фриброз [31, 32].

При гипергаммаглобулинемическом пятнистом васкулите (гиперглобулинемической пурпуре Вальденстрема) поражаются сосуды кожи малого диаметра. На их стенках обнаруживаются отложения иммуноглобулинов. Заболевание развивается у пациентов с гипергаммаглобулинемией (обычно поликлональной, реже - моноклональной) [33].

Волчаночный васкулит обычно протекает с поражением сосудов малого диаметра, наиболее часто посткапиллярных венул, но нередко в воспалительный процесс вовлекаются более крупные сосуды. Гистоло-

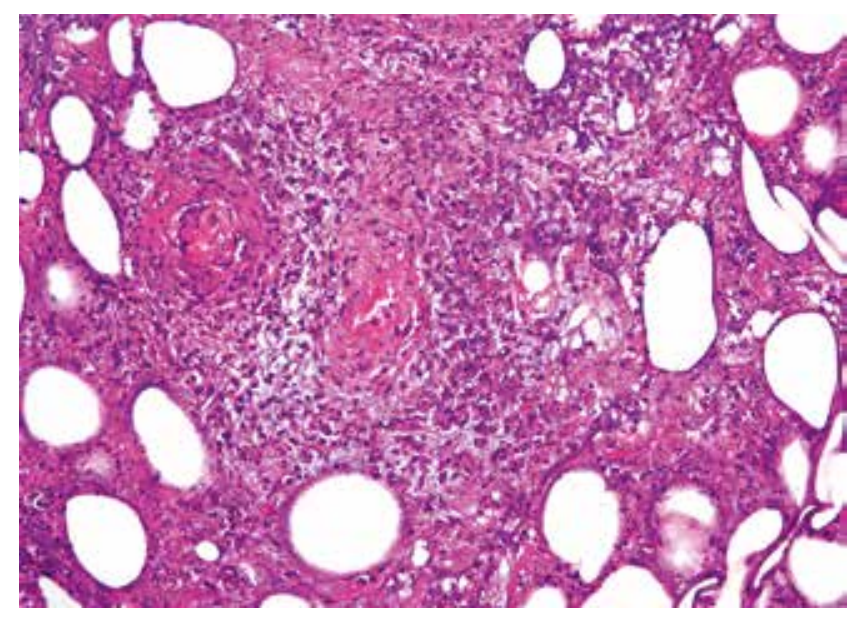

Рис. 4. Нодулярный (узловатый) васкулит. Поражение венул жировых долек (лобулярный васкулит). Некроз и инфильтрация нейтрофильными лейкоцитами стенок вен с явлениями тромбоза

Fig. 4. Nodular (erythema induratum) vasculitis. Lesions of venules of fatty lobules (lobular vasculitis). Necrosis and neutrophilic leukocyte infiltration of vein walls with thrombosis

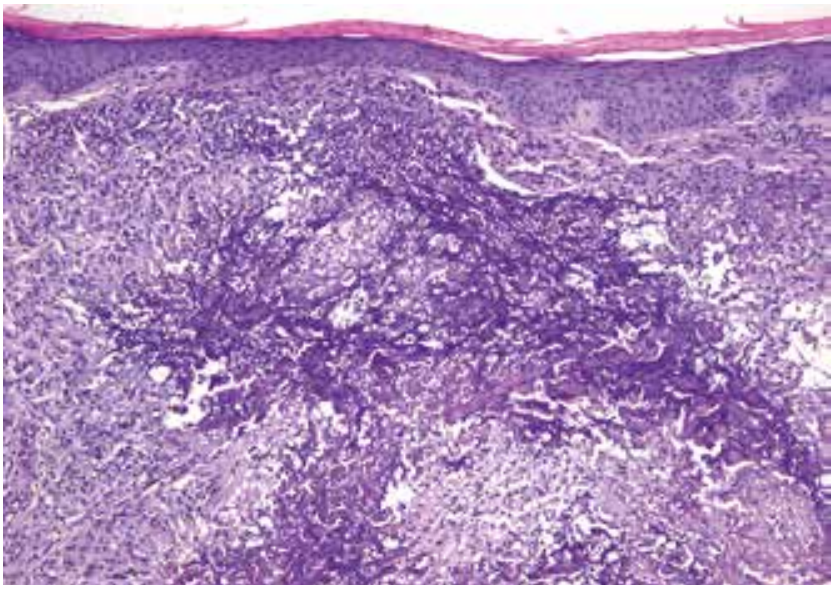

Рис. 6. Ревматоидный васкулит. Некробиотическая палисадообразная гранулема в дерме (т. н. синяя гранулема), нейтросильная инфильтрация с некрозом стенок сосудов малого калибра

Fig. 6. Rheumatoid vasculitis. Necrobiotic palisade granuloma in the dermis (i.e. blue granuloma), and neutrophilic infiltration with necrosis of the small-caliber vessels' walls

гическая картина обычно соответствует варианту лейкоцитокластического васкулита [22].

Ревматоидный васкулит развивается у пациентов с длительным анамнезом ревматоидного артрита, имеющих положительный ревматоидный фактор. Спектр патоморфологических изменений в коже включает варианты поражения от лейкоцитокластического васкулита посткапиллярных венул с депозитами $\operatorname{lgM} / \lg G$, реже - $\lg$ А, до васкулита артерий подкожной клетчатки (гистологическая картина панникулита). При вовлечении в воспаление vasa vasorum процесс может сопровождаться невропатией. Иногда наблюдается воспаление мышечных артерий. Характерным признаком ревматоидного васкулита является частое формирование некробиотических палисадообразных гранулем в дерме (рис. 6). От IgA-васкулита или 
IgM/lgG-васкулита заболевание отличается частым поражением сосудов более крупного диаметра [34].

Васкулит при саркоидозе чаще представлен патоморфологическим вариантом лейкоцитокластического или (реже) - гранулематозного васкулита. В первом случае изменения в коже развиваются на фоне острого саркоидоза, протекающего с лихорадкой и артралгией, и существуют непродолжительное время. Саркоидный гранулематозный васкулит встречается у больных с хроническим течением заболевания [35].

\section{Литература/References}

1. Jennette J.C., Falk R. J., Bacon P. A. et al. 2012 revised International Chapel Hill Consensus Conference Nomenclature of Vasculitides. Arthritis Rheum. 2013; 65: 1-11.

2. Sunderkötter C.H., Zelger B., Chen K.R. et al. Nomenclature of Cutaneous Vasculitis: Dermatologic Addendum to the 2012 Revised International Chapel Hill Consensus Conference Nomenclature of Vasculitides. Arthritis Rheum. 2018 Feb; 70 (2): 171—184.

3. Кожные и венерические болезни: справочник. Под ред. О.Л. Иванова. М.: Медицина, 2007. 352 с. [Skin and sexually transmitted diseases: reference book: Ed. O.L. Ivanova. M: Medicine, 2007. 352 p. (Russia).]

4. Blanco R., Martinez-Taboada V.M., Rodriguez-Valverde V., Garcia-Fuentes M. Cutaneous vasculitis in children and adults. Associated diseases and etiologic factors in 303 patients. Medicine (Baltimore). 1998; 77 (6): 403—418.

5. Garcia-Porrua C., Gonzalez-Gay M.A. Comparative clinical and epidemiological study of hypersensitivity vasculitis versus Henoch-Schönlein purpura in adults. Semin. Arthritis Rheum. 1999; 28 (6): 404—412.

6. Nataraja A., Mukhtyar C., Hellmich B. et al. Outpatient assessment of systemic vasculitis. Best Pract. Res. Clin. Rheum. 2007; 21: 713-732.

7. Piram M., Mahr A. Epidemiology of immunoglobulin A vasculitis (Henoch-Schenlein): current state of knowledge. Curr. Opin. Rheum. 2013; 25: 1718

8. Arora A., Wetter D.A., Gonzalez-Santiago T.M., Davis M.D., Lohse C. M. Incidence of leukocytoclastic vasculitis, 1996 to 2010: a population-based study in Olmsted County. Minnesota. Mayo Clin. Proc. 2014; 89: $1515-1524$.

9. Chen K.R. Skin involvement in ANCA-associated vasculitis. Clin. Exp. Nephrol. 2013; 17: 676-682.

10. Cottin V., Bel E., Bottero P. et al. Revisiting the systemic vasculitis in eosinophilic granulomatosis with polyangiitis (Churg-Strauss): a study of 157 patients by the Groupe d'Etudes et de Recherche sur les Maladies Orphe-lines Pulmonaires and the European Respiratory Society Taskforce on eosinophilic granulomatosis with polyangiitis (Churg-Strauss). Autoimmun. Rev. 2017; 16: 1-9.

11. Irvine A.D., Bruce I. N., Walsh M.Y., Bingham E.A. Microscopic polyangiitis: delineation of a cutaneous-limited variant associated with antimyeloperoxidase autoantibody. Arch. Dermatol. 1997; 133: 474—477.

12. Newell E. L., Mallipeddi R., Murdoch M.E. et al. A case of cutaneous extravascular necrotizing granuloma without systemic manifestations. Clin. Exp. Dermatol. 2007; 32: 509—512.

13. Pendergraft W. F., Niles J.L. Trojan horses: drug culprits associated with antineutrophil cytoplasmic autoantibody (ANCA) vasculitis. Curr Opin Rheumatol 2014; 26: 42-9.

14. Carlson J. A. The histological assessment of cutaneous vasculitis. Histopathology. 2010; 56 (1): 3.

15. Micheletti R.G. Small vessel vasculitis of the skin. Systemic vasculitides: current status and perspectives, 2016; p. 438 (233-244).

16. Sunderkötter $C$., Michl $C$. Cutaneous alterations in vasculitides: Part 1: Nomenclature, classification and correlation between clinical signs and histological features. Internist (Berl). 2019; Aug; 60 (8): 799—804.

17. Xu L.Y., Esparza E. M., Anadkat M. J. et al. Cutaneous manifestations of vasculitis. Semin Arthritis Rheum. 2009; 38 (5): 348-360.
18. Silva de Souza A.W. Autoantibodies in systemic vasculitis. Front. Immunol. 2015; 6: 184

19. Rao D.A., Wei K., Merola J.F. et al. Myeloperoxidase-antineutrophil cytoplasmic antibodies (MPO-ANCA) and proteinase 3-ANCA without immunofluorescent ANCA found by routine clinical testing. I Rheumatol 2015; 42 (5): 847-852.

20. Ratzinger G., Zelger B.G., Carlson J.A., Burgdorf W., Zelger B. Vasculitic wheel: an algorithmic approach to cutaneous vasculitides. J. Dtsch. Dermatol. Ges. 2015; 13: 1092—1117.

21. Marzano A. V., Raimondo M.G., Berti E., Meroni P.L., Ingegnoli F. Cutaneous Manifestations of ANCA-Associated Small Vessels Vasculitis. Clinical Reviews in Allergy \& Immunology. 2017; 53 (3): 428-438.

22. Ramos-Casals M., Stone J.H., Cid M.C., Bosch X. The cryoglobulinaemias. Lancet. 2012; 379: 348-360.

23. Terrier B., Karras A., Kahn J.E. et al. The spectrum of type I cryoglobulinemia vasculitis: newinsights based on 64 cases. Medicine (Baltimore). 2013; 92: 61-68.

24. Mills J.A., Michel B.A., Bloch D.A. et al. The American College of Rheumatology 1990 criteria for the classification of Henoch-Schönlein purpura. Arthritis Rheum. 1990; 33: 1114-1121.

25. Hocevar A., Rotar Z., Jurcic V. et al. IgA vasculitis in adults: the performance of the EULAR/PRINTO/PRES classification criteria in adults. Arthritis Res Ther. 2016 Mar 2; 18: 58.

26. Davis M.D., Daoud M.S., Kirby B., Gibson L.E., Rogers R.S. III. Clinicopathologic correlation of hypocomplementemic and normo-complementemic urticarial vasculitis. J. Am. Acad. Dermatol. 1998; 38: 899—905.

27. Loricera J., Calvo-Rio V., Mata C. et al. Urticarial vasculitis in northern Spain: clinical study of 21 cases. Medicine (Baltimore). 2014; 93: $53-60$.

28. Broekaert S.M., Boer-Auer A., Kerl K. et al. Neutrophilic epitheliotropism is a histopathological clue to neutrophilic urticarial dermatosis. Am. J. Dermatopathol. 2016; 38: 39_ 49.

29. Kim B., LeBoit P.E. Histopathologic features of erythema nodosumlike lesions in Behcet disease: a comparison with erythema nodosum focusing on the role of vasculitis. Am. J. Dermatopathol. 2000; 22: 379—390.

30. Segura S., Pujol R.M., Trindade F., Requena L. Vasculitis in erythema induratum of Bazin: a histopathologic study of 101 biopsy specimens from 86 patients. J. Am. Acad. Dermatol. 2008; 59: 839—851.

31. Wahl C.E., Bouldin M.B., Gibson L.E. Erythema elevatum diutinum: clinical, histopathologic, and immunohistochemical characteristics of six patients. Am. J. Dermatopathol. 2005; 27: 397-400.

32. Kavand S., Lehman J.S., Gibson LE. Granuloma faciale and erythema elevatum diutinum in relation to immunoglobulin G4-related disease: an appraisal of 32 cases. Am. J. Clin. Pathol. 2016; 145: 401—406.

33. Malaviya A. N., Kaushik P., Budhiraja S. et al. Hypergammaglobulinemic purpura of Waldenstrem: report of 3 cases with a short review. Clin. Exp. Rheumatol. 2000; 18: 518-522.

34. Chen K. R., Toyohara A., Suzuki A., Miyakawa S. Clinical and histopathological spectrum of cutaneous vasculitis in rheumatoid arthritis. $\mathrm{Br}$. J. Dermatol. 2002; 147: 905-913.

35. Fernandes S.R., Singsen B.H., Hoffman G.S. Sarcoidosis and systemic vasculitis. Semin. Arthritis Rheum. 2000; 30: 33—46. 


\section{Информация об авторах}

Хайрутдинов Владислав Ринатович - д.м.н., доцент, доцент кафедры кожных и венерических болезней Военно-медицинской академии им. С.М. Кирова; е-mail: haric03@list.ru; тел.: +7 (905) 205-75-99

Белоусова Ирена Эдуардовна - д.м.н., доцент, профессор кафедры кожных и венерических болезней Военно-медицинской академии им. С.М.Кирова; e-mail: mailto:irena.belousova@mail.ru; тел.: +7 (921) 965-12-18

Самцов Алексей Викторович - д.м.н., профрессор, заведующий кафедрой кожных и венерических болезней Военно-медицинской академии им. С. М. Кирова; e-mail: mailto:avsamtsov@mail.ru; тел.: +7 (812) 271-87-81

\section{Information about the authors}

Vladislav R. Khairutdinov - Dr. Sci. (Med.)., Assoc. Prof., Assoc. Prof. of the Department of Skin and Sexually Transmitted Diseases, S. M. Kirov Military Medical Academy, Ministry of Defence of the Russian Federation; e-mail: haric03@list.ru; tel.: +7 (905) 205-75-99

Irena E. Belousova - Dr. Sci. (Med.)., Assoc. Prof., Prof. of the Department of Skin and Sexually Transmitted Diseases, S. M. Kirov Military Medical Academy, Ministry of Defence of the Russian Federation; e-mail: mailto:irena.belousova@mail.ru; tel.: +7 (921) 965-12-18

Aleksey V. Samtsov - Dr. Sci. (Med.)., Prof., Head of the Department of Skin and Sexually Transmitted Diseases, S. M. Kirov Military Medical Academy, Ministry of Defence of the Russian Federation; e-mail: mailto:avsamtsov@mail.ru; tel.: +7 (812) 271-87-81 